\title{
Improving the Wheat Genetic Diversity for End- Use Grain Quality by Chromatin Introgression from the Wheat Wild Relative Dasypyrum villosum
}

\author{
Patrizia Vaccino, Riccardo Banfi, Maria Corbellini, and Ciro De Pace`
}

\begin{abstract}
Most wheat (Triticum aestivum L.) breeding programs rely on gene transfer from the wild and cultivated secondary gene pool (GP-2) for trait enhancement, but none has been successful in improving end-use grain quality using gene transfer from the wild GP-2. In this paper, the efficacy of prolamin subunits encoded by genes of Dasypyrum villosum (L.) Candargy (Dv) for the improvement of wheat end-use grain quality has been assessed by small- and largescale analyses on wheat introgression lines (ILs) derived from Triticum aestivum cv. Chinese Spring $\times D v$ hybridization. Prolamin genes from $D v$ and wheat are coexpressed in the ILs and differentially affect bread-making quality. The ascertained effects correlate weakly with the size of the introgressed $D v$ chromatin and are not confounded by the cryptic variation of the genetic background. Dasypyrum villosum chromatin, including genes at the Glu-V1 locus, significantly improves wheat bread-making quality, and chromatin from the short arm of chromosome $6 \mathrm{~V}$ also improves protein and micronutrient content. These positive effects allow breeders to consider $D v$ as an important source of genes for grain quality improvement in wheat, also in conjunction with the introgression of $D v$ chromatin into wheat for enhancing expression of other traits such as disease resistance.
\end{abstract}

P. Vaccino, R. Banfi, and M. Corbellini, CRA-Unità di Ricerca per la Selezione dei Cereali e la Valorizzazione delle varietà vegetali (SCV), Via Forlani 3, 26866 S. Angelo Lodigiano (LO), Italy; C. De Pace, Dipartimento di Agrobiologia ed Agrochimica (DABAC), Univ. degli Studi della Tuscia, via S. Camillo de Lellis, 01100 Viterbo, Italy. This research was funded by the "Ministero delle politiche agricole alimentari e forestali," Italy, in the framework of the research project FRUMIGEN (D.M.292/7303/05 issued 12 Oct. 2005). Received 8 Apr. 2009. *Corresponding author (depace@unitus.it).

Abbreviations: AFLP, amplified fragment length polymorphism; CDA, canonical discriminant analysis; CDF, canonical discriminant function; CS, Chinese Spring; Dv, Dasypyrum villosum; DSI, Dice similarity index; GLM, generalized linear model; HMW, high molecular weight; ILs, introgression lines; LMW, low molecular weight; PC, protein content; SDS, sodium dodecyl sulphate; SSV, SDS sedimentation volume; SSSV, specific SDS sedimentation volume; TKW, thousandkernel weight.

$\mathrm{T}$ He Wheat (Triticum aestivum L.) crop species has been bred intensively in the past hundred years, and amazing improvements in yield and quality have been achieved (Feuillet et al., 2007). Future yield gains may depend on de novo genetic variation present within the primary gene pool (Rasmusson and Phillips, 1997), but also on the improvement of simple traits based on the identification of novel and superior alleles at specific loci (Collins et al., 2008).

Conventional breeding had in the past the capacity to select new alleles of master genes governing seed traits: examples are the canola (Brassica napus L.) lines low in erucic acid and glucosinolates (Busch et al., 1994; Lühs et al., 1999), the waxy endosperm in wheat (Van Hung et al., 2006), the high amylose content in

Published in Crop Sci. 50:528-540 (2010).

doi: 10.2135/cropsci2009.04.0179

Published online 22 Jan. 2010.

(C) Crop Science Society of America | 677 S. Segoe Rd., Madison, WI 53711 USA

All rights reserved. No part of this periodical may be reproduced or transmitted in any form or by any means, electronic or mechanical, including photocopying, recording, or any information storage and retrieval system, without permission in writing from the publisher. Permission for printing and for reprinting the material contained herein has been obtained by the publisher. 